\title{
Dietary high-polyphenols extra-virgin olive oil is effective in reducing cholesterol content in eggs
}

\author{
Vito Laudadio ${ }^{1 \dagger}$, Edmondo Ceci ${ }^{2}$, Nunzia M B Lastella ${ }^{1}$ and Vincenzo Tufarelli ${ }^{{ }^{* \dagger}}$
}

\begin{abstract}
Background: Extra-virgin olive oil (EVOO) represents an important food in Mediterranean diet due to its favorable effects on human and animal health derived from the consumption of polyphenols. We studied the effects of dietary EVOO differing in polyphenols levels on egg quality.

Methods: A total of 150 laying hens were allotted into three groups over 10 weeks of the experimental period. The three diets were based on wheat-soybean meal with added oils at $2.5 \%$. Hens were fed the following diets: (1) commercial diet containing sunflower oil (Control), (2) diet EVOO from Cima di Bitonto variety (low-polyphenols content; Low-P), and (3) diet EVOO from Coratina variety (high-polyphenols content; High-P). The performance of the hen, the qualitative traits of eggs, and the fatty acid composition and cholesterol content of egg-yolk were measured.

Results: None of the egg productive parameters studied were influenced by dietary treatment, except for yolk color score that was enhanced in hens fed the both EVOO diets $(P<0.05)$. Feeding high-polyphenols EVOO reduced serum cholesterol level in hens $(P<0.01)$ and egg-yolk cholesterol levels (as per egg; $P<0.05$ ). The dietary supplementation of high-polyphenols EVOO raised the polyunsaturated fatty acids (PUFAs) composition and increased the content of oleic and linolenic acids in egg-yolk. Moreover, the atherogenic index in egg-yolk decreased linearly in accordance with increasing levels of dietary polyphenols $(P<0.01)$.
\end{abstract}

Conclusion: In conclusion, a diet for hens consisting of high-polyphenols level from extra-virgin olive oil can improve the fatty acid quality of egg-yolk while lowering the egg-yolk cholesterol level, which could be a beneficial functional food for human health.

Keywords: Extra-virgin olive oil, Cholesterol, Egg quality

\section{Background}

The Mediterranean diet, in which olive oil is the major fat component, has been associated with a lower incidence of coronary heart disease [1]. Extra-virgin olive oil (EVOO) is rich in phenolic compounds which have been shown to delay in vitro metal-induced and radical-dependent low density lipoprotein oxidation [2].

The phenolic content of olive oil depends on a number of factors, but it is mainly dependent on the olive variety as well as oil production and storage [3]. The EVOO, obtained from the fruit of the olive tree solely by mechanical

\footnotetext{
* Correspondence: vincenzo.tufarelli@uniba.it

${ }^{\dagger}$ Equal contributors

'Department of Emergency and Organ Transplantation (DETO), Section of Veterinary Science and Animal Production, University of Study of Bari 'Aldo Moro', Valenzano 70010 Bari, Italy

Full list of author information is available at the end of the article
}

or other physical means under conditions that do not lead to oil alteration, has shown anti-inflammatory, immunomodulatory, antiproliferative and anti-apoptotic effects [4,5]. Traditionally, these health-protective effects have been ascribed to its high polyunsaturated fatty acids (PUFAs) content [6], although, nowadays, it is clear that many of the beneficial effects of EVOO intake are due to its minor highly bioactive components. Phenolic compounds are thought to be related to these beneficial effects receiving the most attention [7]. Oleuropein derivatives, especially hydroxytyrosol, have been shown to have protective effects against markers associated with the atherogenic process [8,9]. Scientific evidence supports the potential use of nutraceuticals focused in polyphenols constituents as agents capable to prevent or accelerate healing of cardiovascular disease [10]. 
Eggs have been considered as a principle food item for human consumption over the history as they provide most of the nutrition as suggested by the recommended daily allowance. The variability in the quality and nutritional values of eggs has a significant impact on consumers' health $[11,12]$. Although eggs are an important source of nutrients due to their high quality protein and variety of vitamins and minerals, it is often recommended that people restrict their consumption since egg yolk contains nearly 30\% lipids and high cholesterol content [13]. Egg consumption is also believed to raise the risk of cardiovascular disease by increasing blood cholesterol levels in hyper-responders and diabetics $[14,15]$ and those groups, as well as persons with elevated LDL-cholesterol levels and heart disease, should limit their dietary cholesterol intake. Dietary fats are known to influence cell membrane, tissues and egg-yolk lipid composition and plasma lipoprotein concentrations depending on their constructive fatty acid content. Due to the health benefits associated with the consumption of phenolic compounds, much research is necessary to enrich different foods of animal origin, such as eggs [16]. For this reason, several studies had been conducted to raise PUFA content in eggs by using dietary fat sources, such as natural oil containing PUFA [17]. Antioxidants of a kind of those natural polyphenols have been used as dietary supplementation [18].

In this way, the role of EVOO-derived bioactive polyphenols on egg quality has never been investigated. Therefore, the best of our knowledge and based on these considerations, the present study was aimed to evaluate the effects of dietary supplementation with EVOO from olive cultivars differing in polyphenols levels on egg quality and egg yolk cholesterol.

\section{Results and discussion}

No literature was located on the effects dietary supplementation with EVOO from olive cultivars differing in polyphenols levels on laying hens productive performance and egg quality; thus, this subject should be considered as a new investigation. In Table 1 are reported the effects of diet including EVOO on the egg production and weight as well as egg qualitative traits of laying hens. The egg-laying rate $(\%)$ were statistically similar $(\mathrm{P}=0.151)$ for all hens on experimental diets with a range of 92.1 in hens on control diet and 92.7 in hens on high-polyphenols diet, indicating uniformity in the laying pattern and quantity of egg laid by the hens fed EVOO as dietary lipid source. The egg weight was also similar $(P=0.062)$ among experimental hens, with a range 62.8 and $63.5 \mathrm{~g}$ for hens fed control or EVOO diet respectively, indicating that the inclusion of the alternative lipid source supported that this egg trait as also previously found by Celebi et al. [19]. The average weight of the eggs conformed and compared positively with values reported for layers in available literatures $[20,21]$.
Table 1 Effect of different dietary extra-virgin olive oil on egg productive and qualitative parameters

\begin{tabular}{|c|c|c|c|c|c|}
\hline \multirow[t]{2}{*}{ Item } & \multicolumn{5}{|l|}{ Diet $^{1}$} \\
\hline & Control & Low-P & High-P & SEM & $P$-value \\
\hline Egg-laying rate, \% & 92.1 & 92.4 & 92.7 & 0.31 & 0.151 \\
\hline Egg weight, g & 62.8 & 63.1 & 63.5 & 0.29 & 0.062 \\
\hline Egg mass, g/hen per day & 57.8 & 58.3 & 58.8 & 0.19 & 0.051 \\
\hline FCR, g feed/g egg & 1.99 & 1.98 & 1.96 & 0.07 & 0.055 \\
\hline Haugh unit & 88.01 & 89.21 & 89.41 & 0.45 & 0.088 \\
\hline Shell thickness $\left(\mathrm{mm} \times 10^{-2}\right)$ & 0.33 & 0.32 & 0.33 & $<0.01$ & 0.436 \\
\hline Shell strength $\left(\mathrm{kg} / \mathrm{cm}^{2}\right)$ & 1.51 & 1.55 & 1.57 & 0.04 & 0.098 \\
\hline Broken + shell-less eggs, \% & 0.15 & 0.16 & 0.17 & $<0.01$ & 0.312 \\
\hline Dirty eggs, \% & 0.40 & 0.38 & 0.39 & $<0.01$ & 0.234 \\
\hline \multicolumn{6}{|l|}{ Egg components, \% } \\
\hline Yolk & 24.5 & 25.1 & 25.3 & 0.17 & 0.051 \\
\hline Albumen & 64.0 & 63.7 & 63.7 & 0.21 & 0.063 \\
\hline Shell & 11.5 & 11.2 & 11.0 & 0.09 & 0.201 \\
\hline Yolk color score & 11.01 & 12.52 & 12.63 & 0.23 & 0.039 \\
\hline
\end{tabular}

'Diets consisted of: Control commercial diet containing sunflower oil; Low-P, low-polyphenols extra-virgin olive oil from Cima di Bitonto cultivar; High-P, high-polyphenols extra-virgin olive oil from Coratina cultivar.

Dietary treatment did not negatively influence any trait related to egg or shell quality (Table 1). The overall values obtained in the present study are quite acceptable for optimal egg quality for this age of hens ( 28 to $38 \mathrm{wk}$ ) in the medium-phase of production. The shell thickness and strength also had similar mean values $(P=0.436)$ among dietary treatments for each parameter, indicating a similar relative density for the eggs. The best index of internal egg quality is the Haugh unit, which is calculated by measuring the height of the inner thick albumen and the egg weight. As it is well known, a reduced Haugh unit indicates deterioration of egg freshness. In the present study, the Haugh unit values were similar $(\mathrm{P}=0.088)$ for the eggs laid by the experimental laying birds. This result is consistent with previous studies where the Haugh unit on the day of lay was not affected by diet supplemented with sunflower or extra-virgin olive oil as the fatty acid and antioxidant source [19]. The egg yolk colour score was increased when both variety of EVOO were included into the diet compared with the control group fed sunflower oil $(P=0.039)$. The influence of EVOO on yolk color observed in our study may be related to the quantity of natural pigments contained in the alternative feed ingredient. In addition to affecting the yolk colour, phenol compounds play a key role as antioxidants in the healthy development of chick embryos, assuring a stronger immune response [22]. Nevertheless, it is clear that the dietary variation in polyphenols is not the only factor that produces individual differences: an important role of breed, age and season was reported [23]. 
Serum and egg-yolk total cholesterol decreased linearly for hens given diets supplemented with EVOO (Table 2). The concentrations of total cholesterol in the egg-yolk were within or lower the ranges reported in laying hens [24-26]. Feeding high-polyphenols may increase the oxidative stability and provide a source of compounds that are useful for human nutrition and health. High-polyphenols EVOO supplementation in hens' diet markedly decreased $(\mathrm{P}<0.01)$ serum and yolk total cholesterol levels. In particular, Low-P and High-P treatments reduced cholesterol by 6.76 and $10.68 \%$ (on a per g of yolk basis), respectively, whereas on a per total yolk basis, Low-P and High-P reduced cholesterol by 4.04 and $6.74 \%$, respectively.

The cholesterol is essential for the development of the embryo, and many researchers have tried to decrease the amount of cholesterol in egg yolk due to its risk for cardiovascular disease in humans [11,27]. Azeke and Ekpo [28] suggested that natural polyphenols, catechins, and flavonols have a cholesterol lowering effect on egg by scavenging reactive oxygen species and chelating metal ions. The dietary supplementation of high-polyphenols EVOO may result in a synergistic effect of linoleic acid in decreasing the cholesterol content of egg-yolk. In a

Table 2 Effect of different dietary extra-virgin olive oil on serum and egg-yolk cholesterol levels and egg-yolk fatty acid profile

\begin{tabular}{|c|c|c|c|c|c|}
\hline \multirow[t]{2}{*}{ Item } & \multicolumn{5}{|l|}{ Diet $^{1}$} \\
\hline & Control & Low-P & High-P & SEM & $P$-value \\
\hline \multicolumn{6}{|l|}{ Serum } \\
\hline Cholesterol, mg/dl & 124.5 & 100.2 & 97.6 & 6.86 & 0.004 \\
\hline \multicolumn{6}{|l|}{ Yolk } \\
\hline Cholesterol, mg/g yolk & 13.01 & 12.13 & 11.62 & 0.332 & 0.007 \\
\hline Cholesterol, mg total yolk & 200.2 & 192.1 & 186.7 & 0.703 & 0.029 \\
\hline \multicolumn{6}{|l|}{ Yolk fatty acid, $\%$ on total FA } \\
\hline C14:0 Myristic & 2.02 & 1.74 & 0.63 & 0.011 & 0.032 \\
\hline C14:1 n-5 Myristoleic & 1.11 & 1.55 & 0.47 & 0.013 & 0.010 \\
\hline C16:0 Palmitic & 39.32 & 32.97 & 34.49 & 0.071 & 0.005 \\
\hline C16:1 n-7 Palmitoleic & 2.01 & 3.02 & 2.11 & 0.052 & 0.052 \\
\hline C18:0 Stearic & 15.06 & 16.77 & 16.51 & 0.045 & 0.059 \\
\hline C18:1 Oleic & 27.22 & 29.66 & 29.32 & 0.062 & 0.011 \\
\hline C18:2 Linoleic & 12.70 & 12.22 & 15.39 & 0.036 & 0.017 \\
\hline C18:3 Linolenic & 0.56 & 1.07 & 1.08 & 0.010 & 0.010 \\
\hline$\Sigma$ SFA & 56.40 & 52.48 & 51.63 & 0.141 & 0.025 \\
\hline$\Sigma$ MUFA & 30.34 & 34.23 & 31.90 & 0.202 & 0.051 \\
\hline$\Sigma$ PUFA & 13.26 & 13.29 & 16.47 & 0.152 & 0.012 \\
\hline Saturated/Unsaturated & 1.29 & 1.10 & 1.08 & 0.015 & 0.030 \\
\hline Atherogenic index ${ }^{2}$ & 1.09 & 0.86 & 0.77 & 0.009 & 0.009 \\
\hline
\end{tabular}

${ }^{1}$ Diets consisted of: Control commercial diet containing sunflower oil; Low-P, low-polyphenols extra-virgin olive oil from Cima di Bitonto cultivar; High-P, high-polyphenols extra-virgin olive oil from Coratina cultivar; ${ }^{2}$ Calculated according to the equation proposed by Ulbricht and Southgate [30]. recent trial, Zhang and Kim [26] suggested that the mechanism by which olive oil improves the absorption of vitamin A, another fat-soluble vitamin, might facilitate an increase in cholesterol levels in the sera of laying hens.

Table 2 presents the fatty acid compositions of the yolks from eggs of hens submitted to the three treatments. Analysis of fatty acid methyl esters from the egg-yolk lipids of hens revealed they were influenced by the dietary treatments. Egg lipids from hens fed High-P diet showed lower $(\mathrm{P}<0.01)$ values of $\mathrm{C} 14: 0, \mathrm{C} 16: 0$ than those in control eggs. However, C18:0 did not significantly vary among the three treatments. Hens fed diets with EVOO showed higher $(\mathrm{P}<0.01)$ mean values of $\mathrm{C} 18: 1$ than those hens fed with control diet. The egg-yolk from high-polyphenols diet showed higher $(\mathrm{P}<0.01)$ levels of fatty acids $\mathrm{C} 18: 2$ and C18:3 compared to the other dietary groups. A significant decrease of SFA percentage and an increase of the PUFA were observed in eggs from hens fed high-polyphenols EVOO in comparison to the control eggs. In any of the dietary treatments containing EVOO, there was a better saturated to unsaturated fatty acid ratio in comparison with the values obtained for the control eggs. Therefore, it is possible to affirm that all the diets containing EVOO, especially when contained high-polyphenols level, resulted in eggs of higher quality than the control conventional eggs. Even though the SFA/UFA ratio is an important factor from a human nutrition point of view, specific SFA and PUFA have different metabolic effects [29]. Fatty acids can either promote or prevent atherosclerosis and coronary thrombosis, based on their effects on serum cholesterol and low density lipoprotein cholesterol concentrations. For this reason, the atherogenic index have been introduced [30]. The atherogenic index of the egg-yolk lipids differed significantly among dietary treatments, and varied from 1.09, in control diet, to 0.86 and 0.77 in Low-P and High-P diets, respectively (Table 2). The egg-yolks from hens fed high-polyphenols EVOO were characterised by the lowest atherogenic index value, which were related to their lower SFA/UFA ratio. Low values of atherogenic index is recommended for a healthy diet [31]. The C14:0 and C16:0 fatty acids are known to be among the most atherogenic, while C18:0 is thought to be neutral with respect to atherogenicity, but is instead considered to be thrombogenic [32]. Another positive feature arising from the egg-yolk lipid profile in this study was the low or quite similar values for both the atherogenic index, when compared to other meat product [33] or seafood [34].

\section{Conclusions}

In conclusion, after 10 weeks of treatment with each diet type, our results show that EVOO can have high nutritional value. These findings indicate that a supplementation of laying hens with high-polyphenols EVOO reduces 
egg-yolk cholesterol and enhances the fatty acid profile of yolk lipids, so the use of this oil could have advantages for egg producers as well as advantageous for human nutrition. These findings could have significant consequences for human health and thus deserve further investigation.

\section{Methods}

\section{Experimental birds and management}

This study was conducted in the experimental poultry facility located at the University of Bari 'Aldo Moro', Italy, observing the animal welfare Legislative Decree 116/92, Council Directive 98/58/EC, received in Italy by Legislative Decree 146/2001, and Council Directive 2007/43/CE, received in Italy by the governmental Decree 181/2010 and Legislative Decree 267/2003. A total of 150 ISA Brown laying hens, $18 \mathrm{wk}$ of age, were free-range reared under natural light:dark cycle. The hens were divided into three groups of fifty hens each (two replicates each of 25 birds/group) and were housed in different indoor pens $\left(0.15 \mathrm{~m}^{2} / \mathrm{bird}\right)$ equipped with feeders and drinkers, with free access to open air runs $\left(3 \mathrm{~m}^{2} /\right.$ bird $)$.

\section{Dietary treatments}

The diets were based on wheat and soybean meal with added oils at $2.5 \%$. The dietary oils included sunflower oil (Control), extra virgin olive oil from Cima di Bitonto variety (low-polyphenols content; Low-P), and extra virgin olive oil from Coratina variety (high-polyphenols content; High-P) (Table 3). The extra-virgin olive oils used for experimental diets had a low- and high- total phenol concentration (138 vs. $254 \mathrm{mg} / \mathrm{kg}$ ) with an different hydroxytyrosol concentrations (17 vs. $43 \mathrm{mg} / \mathrm{kg}$ ), for Cima di Bitonto and Coratina variety respectively (Table 4); as determined by Oliveras-López et al. [9]. The sunflower oil used for control diet had very low levels of total polyphenols [35]. The oils were kept in cold room at $4^{\circ} \mathrm{C}$ prior mixing and the diets were prepared weekly and kept in cold room in air-tight containers. The diets were isocaloric and isonitrogenous containing $17.0 \%$ of crude protein (CP) and 2,680 kcal of metabolizable energy $/ \mathrm{kg}$ of diet, designed to meet or exceed the nutrient requirements for laying hens [36]. The experimental diets were fed to the animals for 10 weeks. Feed and water were provided ad libitum throughout the entire trial. Extra-virgin olive or sunflower oils supplementation did not influence feed intake (data not shown). Hens' mortality was recorded as occurred.

\section{Sample collection and procedures}

Samples of diets were ground in a hammer mill with a $1 \mathrm{~mm}$ screen and analysed in triplicate for dry matter (DM, 945.15), ash (967.05), crude protein (CP, Kjeldahl $\mathrm{N} \times 6.25,990.03)$, crude fiber (978.10) and ether extract (945.16) according to AOAC International [37].
Table 3 Ingredients and chemical analysis of control and experimental diets fed to laying hens

\begin{tabular}{|c|c|c|}
\hline \multirow[b]{2}{*}{ Ingredients, $\mathrm{g} / \mathrm{kg}$ as-fed basis } & \multicolumn{2}{|l|}{ Diet } \\
\hline & Control & Experimental \\
\hline Corn & 541.0 & 541.0 \\
\hline Soybean meal (48\% CP) & 175.0 & 175.0 \\
\hline Calcium carbonate & 90.0 & 90.0 \\
\hline Wheat & 75.0 & 75.0 \\
\hline Alfalfa meal (17\% CP) & 45.0 & 45.0 \\
\hline Corn gluten meal $(60 \% \mathrm{CP})$ & 45.0 & 45.0 \\
\hline Sunflower oil & 25.0 & - \\
\hline Extra-virgin olive oil ${ }^{1}$ & - & 25.0 \\
\hline Dicalcium phosphate & 17.0 & 17.0 \\
\hline Vitamin-mineral premix ${ }^{2}$ & 2.5 & 2.5 \\
\hline Sodium chloride & 2.5 & 2.5 \\
\hline Sodium bicarbonate & 2.5 & 2.5 \\
\hline DL-Met & 2.0 & 2.0 \\
\hline L-Lys $\mathrm{HCl}$ & 2.0 & 2.0 \\
\hline Yeast & 1.5 & 1.5 \\
\hline Thr & 1.0 & 1.0 \\
\hline \multicolumn{3}{|l|}{ Chemical analysis, \% } \\
\hline Dry matter & 87.54 & 87.95 \\
\hline Crude protein & 16.85 & 16.71 \\
\hline Crude fibre & 3.22 & 3.47 \\
\hline Crude fat & 5.74 & 5.81 \\
\hline Ash & 13.21 & 13.15 \\
\hline \multicolumn{3}{|l|}{ Calculated analysis } \\
\hline ME (kcal/kg of diet) & 2,836 & 2,893 \\
\hline Lys, \% & 0.86 & 0.85 \\
\hline $\mathrm{Ca}, \%$ & 4.05 & 4.08 \\
\hline Met + Cys, \% & 0.74 & 0.75 \\
\hline Available P, \% & 0.36 & 0.37 \\
\hline
\end{tabular}

Data for chemical analyses are presented as mean values of five observations per treatment.

${ }^{1}$ Experimental diets consisted of: low-polyphenols extra-virgin olive oil from Cima di Bitonto cultivar and high-polyphenols extra-virgin olive oil from Coratina cultivar

${ }^{2}$ Provided per kg of product: 2,500.000 IU vitamin A; 300,000 IU vitamin $\mathrm{D}_{3}$. 7,500 mcg 25-hydroxycholecalciferol; 6,000 mg vitamin $\mathrm{E}_{;} 500 \mathrm{mg}$ vitamin $\mathrm{K}_{3}$; $4,000 \mathrm{mg}$ vitamin PP; $300 \mathrm{mg}$ vitamin $B_{1} ; 1,000 \mathrm{mg}$ vitamin $B_{2} ; 2,000 \mathrm{mg}$ D-pantothenic acid; $400 \mathrm{mg}$ vitamin $\mathrm{B}_{6} ; 3 \mathrm{mg}$ vitamin $\mathrm{B}_{12} ; 150 \mathrm{mg}$ folic acid; 20 mg D-biotin; 10,000 mg Fe; 1,000 mg Cu; 30,000 mg Mn; 40 mg Co; $15,000 \mathrm{mg} \mathrm{Zn;} 200 \mathrm{mg} \mathrm{l} ; 20 \mathrm{mg}$ Se.

Eggs were collected daily and egg production was calculated on a hen-day basis. Eggs with any adhering manure were classed as dirty, and the percentage calculated. Eggs produced the last day of each week on trial were individually weighed. Egg mass production per hen per day was calculated as laying percentage multiplied by average egg weight of the hen. Feed conversion ratio (FCR) was calculated as gram feed consumption per day per hen divided 


\begin{tabular}{|c|c|c|c|}
\hline \multirow[t]{2}{*}{ Determined by HPLC ${ }^{1}$} & \multicolumn{2}{|c|}{ Extra-virgin olive oil } & \multirow[b]{2}{*}{ SEM } \\
\hline & Cima di Bitonto & Coratina & \\
\hline \multicolumn{4}{|l|}{ Phenol composition } \\
\hline Hydroxytyrosol & 16.92 & 42.98 & 0.052 \\
\hline Tyrosol & 16.98 & 66.25 & 0.045 \\
\hline 3,4-DHPEA-EDA & 32.63 & 39.44 & 0.021 \\
\hline$p$-HPEA-EDA & 7.93 & 38.42 & 0.016 \\
\hline (+)-1-Acetoxypinoresinol & 11.44 & 24.16 & 0.014 \\
\hline (+)-Pinoresinol & 2.47 & 13.34 & 0.009 \\
\hline Luteolin & 4.16 & 5.25 & 0.005 \\
\hline 3,4-DHPEA-EA & 1.77 & 14.64 & 0.019 \\
\hline Apigenin & 3.82 & 4.51 & 0.003 \\
\hline$p$-HPEA-EA & 2.29 & 4.59 & 0.002 \\
\hline Total phenols & 137.85 & 253.58 & 0.521 \\
\hline \multicolumn{4}{|l|}{ Fatty acid composition } \\
\hline C16:0 Palmitic & 18.75 & 14.77 & 0.201 \\
\hline C18:1 Oleic & 72.71 & 77.07 & 0.147 \\
\hline C18:2 Linoleic & 7.79 & 7.04 & 0.198 \\
\hline C18:3 Linolenic & 0.75 & 1.12 & 0.075 \\
\hline
\end{tabular}

${ }^{1}$ Each value represents the mean of five replicate analyses; SEM, standard error of the means.

by gram egg mass per day per hen Eggs were analyzed for their interior and exterior quality as reported by Laudadio and Tufarelli [30]. Eggs were examined for shell quality by specific gravity. Shell thickness (with shell membrane) of the eggs ( $10 \%$ of the daily egg produced) was measured by micrometer. Shell thickness was a mean value of measurements at 3 locations on the eggs (air cell, equator, and sharp end). Breaking strength of uncracked eggs was determined with a testing machine (model 1140, Instron Ltd., Bucks, UK). Egg components (as albumen, yolk and shell) were measured by weekly breakouts on two eggs per replicate pen and expressed as percentage of egg weight. The Haugh unit was calculates as: Haugh units $(\%)=$ $100 \times \log \left(\mathrm{H}+7.57-1.7 \mathrm{~W}^{0.37}\right.$, where $\mathrm{H}$ is the height of the albumen and $\mathrm{W}$ is the weight of the egg) according the formula proposed by Card and Nesheim [38]. Egg yolk color was scored using the 15-point scale (colour scale from 15, dark orange to 1, light pale) of the DSM yolk color fan (DSM Nutritional Products Ltd., Basel, Switzerland). Blood samples $(2.0 \mathrm{ml})$ from each individual layer were collected weekly during the whole feeding period. Blood was collected from the brachial wing vein using sterilized syringes and needles. After $1 \mathrm{~h}$ standing at room temperature, serum was isolated by centrifugation at
$1,150 \times g$ for $10 \mathrm{~min}$. Serum samples were stored at $-80^{\circ} \mathrm{C}$ until further analysis.

\section{Yolk and serum cholesterol contents}

The yolk cholesterol concentrations were determined sampling egg yolks ( $1 \mathrm{~g}$ ) weekly saponified with $20 \mathrm{ml}$ of $33 \%$ ethanolic $\mathrm{KOH}$ in tightly-capped tubes placed in a $60^{\circ} \mathrm{C}$ water bath for $1 \mathrm{~h}$. The mixture was then cooled in ice water, and $5 \mathrm{ml}$ of distilled water was added. Cholesterol in unsaponifiable fractions was extracted twice with $5 \mathrm{ml}$ of hexane. The resulting aliquot of hexane containing cholesterol was dried under nitrogen, redissolved in $5 \mathrm{ml}$ of hexane, and injected into a gas chromatograph (HP-6890 N, Palo Alto, CA, USA). $5 \alpha$-cholestane (Sigma-Aldrich) was used as an internal standard. A split inlet (split ratio, 100:1) was used to inject samples into a capillary column (HP-5, Agilent, Steven, CA, USA; $30 \mathrm{~m} \times 0.53 \mathrm{~mm} \times 0.5 \mu \mathrm{m}$ ), and the ramped oven temperature was $270^{\circ} \mathrm{C}$ isothermal, detector temperature was $300^{\circ} \mathrm{C}$, and inlet temperature was $210^{\circ} \mathrm{C}$. The $\mathrm{N}_{2}$ served as the carrier gas at a constant flow rate of $1.0 \mathrm{ml} / \mathrm{min}$. Total cholesterol concentrations in the plasma was analysed independently by UV spectrophotometer using commercial kits (Diasys, Diagnostic systems, Germany).

\section{Polyphenols and fatty acid analyses}

Quantitative and qualitative analysis of phenolic fraction of the extra virgin olive oils was performed according to the COI/T20/29doc (International Olive Council) for olive oil. The method is based on direct extraction of the phenolic minor polar compounds from olive oil by means of a methanol solution and subsequent quantification by high-performance ternary gradient liquid chromatograph (HPLC) [5]. After direct extraction of the phenolic minor polar compounds by means of a methanol solution, an aliquot of the supernatant phase was taken and filtered through a $0.45-\mathrm{mm}$ PVDF filter, injected into the HPLC system equipped with $\mathrm{C} 18$ reverse-phase column $(4.6 \mathrm{~mm} \times$ $25 \mathrm{~cm})$, type Spherisorb ODS-2 $(5 \mathrm{~mm}), 100 \mathrm{~A}^{\circ}$, with spectrophotometric UV detector at $280 \mathrm{~nm}$ and integrator. The content of the biophenols was expressed in milligrams of tyrosol per kilogram of oil and was calculated by measuring the sum of the areas of the related chromatographic peaks. The composition of the isolated phenolic fraction is detailed in Table 4.

In preparation for fatty acid (FA) composition analysis, samples of oil and egg-yolk (5 g each) were freeze-dried. Briefly, methyl heptadecanoate (no. 51633, Fluka, St. Louis, MO) was dissolved into $\mathrm{n}$-hexane $(1 \mathrm{mg} / \mathrm{mL})$ as an internal standard. Methyl esters of the FA were prepared [39]; samples (300 $\mathrm{mg}$ each) and $5 \mathrm{~mL}$ of internal standard were incubated $\left(2 \mathrm{~h}\right.$ at $\left.80^{\circ} \mathrm{C}\right)$ with methanolic acetyl chloride in a total volume of $9 \mathrm{~mL}$. After cooling to room temperature, $7 \mathrm{~mL}$ of $7 \%\left(\mathrm{wt} / \mathrm{vol}\right.$ ) $\mathrm{K}_{2} \mathrm{CO}_{3}$ was 
added with mixing, and then the organic phase was collected after centrifuging at $1,500 \times g$ for $2 \mathrm{~min}$ at $4^{\circ} \mathrm{C}$. The FA methyl esters were fractionated over a CPSIL883 column $(100 \mathrm{~m} \times 0.25 \mathrm{~mm}$ i.d., film thickness $0.20-\mu \mathrm{m}$ fused silica; Varian, Palo Alto, CA) in a Shimadzu (model 2GC17A, Shimadzu, Kyoto, Japan) gas chromatograph with a Hewlett-Packard HP 6890 gas system (Palo Alto, CA) and using flame ionization detection. Helium was used as the carrier gas at a constant flow rate of $1.7 \mathrm{~mL} / \mathrm{min}$. The oven temperature was programmed as follows: $175^{\circ} \mathrm{C}$, held for $4 \mathrm{~min} ; 175$ to $250^{\circ} \mathrm{C}$ at $3^{\circ} \mathrm{C} / \mathrm{min}$; and then maintained for $20 \mathrm{~min}$. The injector port and detector temperature was $250^{\circ} \mathrm{C}$. Samples $(1 \mu \mathrm{L})$ were injected by an auto-sampler. Output signals were identified and quantified from the retention times and peak areas of known calibration standards. Composition was expressed as percentages of the total FA. The atherogenic index was calculated according to the equation proposed by Ulbricht and Southgate [30].

\section{Statistical analysis}

Data were analyzed using the one-way ANOVA option of the GLM of SAS/STAT software [40] as a completely randomized design with the dietary treatments or oil sources as main effects. The statistical model used was: $Y_{\mathrm{ijk}}=\mu+P_{\mathrm{i}}+$ $R_{\mathrm{ij}}+\varepsilon_{\mathrm{ijk}}$, where $\mathrm{Y}_{\mathrm{ijk}}=$ response variables from each individual replication or pen, $\mu=$ the overall mean; $P_{i}=$ the effect of dietary oil source; $R_{i j}=$ the inter-experimental unit (replications) error term; and $\varepsilon_{\mathrm{ijk}}=$ the intra-experimental unit error term. When there was a significant $F$-value, means were compared by the Student-Newman-Keul's method. Significance implies $\mathrm{P}<0.05$ unless stated otherwise.

\section{Competing interests}

The authors declare that they have no competing interests.

\section{Authors' contributions}

$\mathrm{VL}$ : performed experiments, conception and design of research, interpreted results of experiments; EC: performed experiments; NMBL: performed experiments; VT: performed experiments, analysed data, interpreted results of experiments, drafted manuscript, edited and revised manuscript, approved final version of manuscript. All authors read and approved the final manuscript.

\section{Acknowledgements}

The Authors are thankful to "Azienda Agricola Dr. Giuseppe Colia; Olearia AIPO Puglia Società Cooperativa Agricola, Andria (BT), Italy" for the supply of the Coratina cultivar extra virgin olive oil to carry out this work.

\section{Author details}

'Department of Emergency and Organ Transplantation (DETO), Section of Veterinary Science and Animal Production, University of Study of Bari 'Aldo Moro', Valenzano 70010 Bari, Italy. 'Department of Veterinary Medicine, University of Bari 'Aldo Moro', Valenzano 70010 Bari, Italy.

Received: 17 November 2014 Accepted: 17 January 2015 Published online: 07 February 2015

\section{References}

1. Renaud S, de Lorgeril M, Delaye J, Guidollet J, Jacquard F, Mamelle N, et al. Cretan Mediterranean diet for prevention of coronary heart disease. Am J Clin Nutr. 1995;61:1360-7.
2. Owen RW, Giacosa A, Hull WE, Haubner R, Würtele G, Spiegelhalder B, et al. Olive-oil consumption and health: the possible role of antioxidants. Lancet Oncol. 2000;1:107-12.

3. Aguilera MP, Beltrán G, Ortega D, Fernández A, Jiménez A, Uceda M. Characterisation of virgin olive oil of Italian olive cultivars: Frantoio and Leccino, grown in Andalusia. Food Chem. 2005;89:387-91.

4. Escrich E, Moral R, Solanas M. Olive oil, an essential component of the Mediterranean diet, and breast cancer. Public Health Nutr. 2011;14:2323-32.

5. Sánchez-Fidalgo S, Cárdeno A, Sánchez-Hidalgo M, Aparicio-Soto M, de la Lastra CA. Dietary extra virgin olive oil polyphenols supplementation modulates DSS-induced chronic colitis in mice. J Nutr Biochem. 2013:24:1401-13.

6. Bermudez B, Lopez S, Ortega A, Varela LM, Pacheco YM, Abia R, et al. Oleic acid in olive oil: from a metabolic framework toward a clinical perspective. Curr Pharm Des. 2011;17:831-43.

7. Bondia-Pons I, Schroder H, Covas MI, Castellote Al. Moderate consumption of olive oil by healthy European men reduces systolic blood pressure in non-mediterranean participants. J Nutr. 2007;137:84-7.

8. Andreadou I, Iliodromitis EK, Mikros E, Constantinou M. The olive constituent oleuropein exhibits anti-ischemic, antioxidative, and hypolipidemic effects in anesthetized rabbits. J Nutr. 2006;136:2213-9.

9. Oliveras-López MJ, Berná G, Carneiro EM, de la Serrana HLG, Martín F, López MC. An extra-virgin olive oil rich in polyphenolic compounds has antioxidant effects in OF1 mice. J Nutr. 2008;138:1074-8.

10. Romano M, Vitaglione P, Sellitto S, D'Argenio G. Nutraceuticals for protection and healing of gastrointestinal mucosa. Curr Med Chem. 2012:19:109-17.

11. Elkin RG. Reducing shell egg cholesterol content. I. Overview, genetic approaches, and nutritional strategies. World Poult Sci J. 2006;62:665-87.

12. Attia YA, Al-Harthi MA, Shiboob MM. Evaluation of quality and nutrient contents of table eggs from different sources in the retail market. Ital J Anim Sci. 2014;1:369-76.

13. Jung $\mathrm{S}, \mathrm{Han} \mathrm{BH}, \mathrm{Nam} \mathrm{K}$, Ahn DU, Lee JH, Jo C. Effect of dietary supplementation of gallic acid and linoleic acid mixture or their synthetic salt on egg quality. Food Chem. 2011;129:822-9

14. Weggemans RM, Zock PL, Katan MB. Dietary cholesterol from eggs increases the ratio of total cholesterol to high-density lipoprotein cholesterol in humans: a meta-analysis. Am J Clin Nutr. 2001;73:885-91.

15. Elkin RG. Reducing shell egg cholesterol content. II. Review of approaches utilizing non-nutritive dietary factors or pharmacological agents and an examination of emerging strategies. World Poult Sci J. 2007;63:5-32.

16. Gladine C, Morand C, Rock E, Bauchart D, Durand D. Plant extracts rich in polyphenols (PERP) are efficient antioxidants to prevent lipoperoxidation in plasma lipids from animals fed n-3 PUFA supplemented diets. Anim Feed Sci Technol. 2007:136:281-96.

17. Lawlor JB, Gaudette N, Dickson T, House JD. Fatty acid profile and sensory characteristics of table eggs from laying hens fed diets containing microencapsulated fish oil. Anim Feed Sci Technol. 2010;156:97-103.

18. Visioli F, Bernardini E. Extra virgin olive oil's polyphenols: biological activities. Curr Pharm Des. 2011;17:786-804.

19. Celebi S, Utlu N, Aksu MI. Effects of different fat sources and levels on the fatty acid composition in different tissues of laying hens. J Appl Anim Res. 2011:39:25-8.

20. Baucells MD, Crespo N, Barroeta AC, Lopez-Ferrer S, Grashorn MA. Incorporation of different polyunsaturated fatty acids into eggs. Poult Sci. 2000;79:51-9.

21. Laudadio V, Tufarelli V. Treated fava bean (Vicia faba var. minor) as substitute for soybean meal in diet of early phase laying hens: Egg-laying performance and egg quality. Poult Sci. 2010;89:2299-303.

22. Dong XF, Gao WW, Tong JM, Jia HQ, Sa RN, Zhang Q. Effect of polysavone (alfalfa extract) on abdominal fat deposition and immunity in broiler chickens. Poult Sci. 2007:86:1955-9.

23. Cucco M, Guasco B, Malacarne G, Ottonelli R. Effects of $\beta$-carotene on adult immune condition and antibacterial activity in the eggs of the Grey Partridge (Perdix perdix). Comp Biochem Physiol A-Mol Integr Physiol. 2007;2007(147):1038-46.

24. Simčič M, Stibilj VA, Holcman A. The cholesterol content of eggs produced by the Slovenian autochthonous Styrian hen. Food Chem. 2009:114:1-4.

25. Sinanoglou VJ, Strati IF, Miniadis-Meimaroglou S. Lipid, fatty acid and carotenoid content of edible egg yolks from avian species: a comparative study. Food Chem. 2011;124:971-7. 
26. Zhang ZF, Kim IH. Effects of dietary olive oil on egg quality, serum cholesterol characteristics, and yolk fatty acid concentrations in laying hens. J Appl Anim Res. 2014;42:233-7.

27. Viveros A, Centeno C, Arija I, Brenes A. Cholesterol-lowering effects of dietary lupin (Lupinus albus var multolupa) in chicken diets. Poult Sci. 2007;86:2631-8.

28. Azeke MA, Ekpo KE. Egg yolk cholesterol lowering effects of garlic and tea. J Med Plant Res. 2009:3:1113-7.

29. Simopoulos AP. The importance of the ratio of omega-6/omega-3 essential fatty acids. Biomed Pharmacother. 2002;56:365-79.

30. Ulbricht TLV, Southgate DAT. Coronary heart disease: seven dietary factors. Lancet. 1991;338:982-92.

31. Mutungi G, Ratliff J, Puglisi M, Torres-Gonzalez M, Vaishnav U, Leite JO, et al. Dietary cholesterol from eggs increases plasma HDL cholesterol in overweight men consuming a carbohydrate-restricted diet. J Nutr. 2008;138:272-6.

32. Laudadio $V$, Tufarelli $V$. Influence of substituting dietary soybean meal for dehulled-micronized lupin (Lupinus albus Cv. Multitalia) on early phase laying hens production and egg quality. Livest Sci. 2011;140:184-8.

33. Furman M, Malovrh Š, Levart A, Kovač M. Fatty acid composition of meat and adipose tissue from Krškopolje pigs and commercial fatteners in Slovenia. Arch Tierz. 2010;53:73-84.

34. Popa CD, Arts E, Fransen J, van Riel LP: Atherogenic index and high-density lipoprotein cholesterol as cardiovascular risk determinants in rheumatoid arthritis: the impact of therapy with biologicals. Mediat Inflamm 2012, doi:10.1155/2012/785946

35. De Leonardis A, Macciola V, Di Domenico N. A first pilot study to produce food antioxidant from sunflower seed shells (Helianthus annus). Eur I Lipid Sci Technol. 2005;107:220-7.

36. National Research Council. Nutrient Requirements for Poultry. 9th rev. ed. Washington, DC: National Academy Press; 1994.

37. AOAC International. Official Methods of Analysis of AOAC International. 17th ed. Gaithersburg, MD, USA: AOAC International; 2000.

38. Card LE, Nesheim MC. Poultry Production. 11th ed. Philadelphia, PA: Lea and Febiger; 1972.

39. Sukhija PS, Palmquist DL. Rapid method for determination of total fatty acid content and composition of feedstuffs and feces. J Agric Food Chem. 1988;36:1202-6.

40. SAS Institute. SAS/STAT User's Guide. Release 8.1. Statistical Analysis System. Cary, NC, USA: SAS Institute Inc; 2004.

\section{Submit your next manuscript to BioMed Central and take full advantage of:}

- Convenient online submission

- Thorough peer review

- No space constraints or color figure charges

- Immediate publication on acceptance

- Inclusion in PubMed, CAS, Scopus and Google Scholar

- Research which is freely available for redistribution 